\title{
ŽANROVSKI POTENCIJAL 18. VEKA I HOMO EUROPAEUS
}

\section{Miodrag Maticki}

UDK: 7.041.7:821.163.4“17“

\begin{abstract}
Rezime: Ako se ljudskoj istoriji priđe kao istoriji civilizacije, istoriji ideja, tj. ako se prepustimo evropeizaciji istorijske slike, Evropa jeste najznačajniji prostor na kojem dolazi u 18. veku do intenzivnog sažimanja i prožimanja uticaja Istoka i Zapada. Posebno značajno mesto zauzima Habsburška monarhija, ne toliko prostorno-geografski, već kao preoblikovani kulturni koncept prosvećenog apsolutizma, kao i centralno-istočni sa kulturnim tokovima u kojima protrajava vizantijska i pravoslavna tradicija. A kada je reč o interkulturalnim aspektima „prosvećene“ modernizacije, o rađanju evropejstva centralno-istočnog čoveka, svakako su važni hrvatsko-srpski odnosi i prožimanja, posebno kada je reč o stasavanju novog evropskog čoveka i ideje savremenog sveta kroz preispitivanje socijalnog, političkog i istorijskog konteksta diskusije o „evropskoj tradiciji“. U 18. veku na južnoslovenskim prostorima značajno je pitanje početaka periodike, posebno kod Hrvata i Srba u evropskom kontekstu, pod najčešće nemačkim, mađarskim i ruskim uzorima. Reč je o cvetnicima, magazinima, zabavnicima, koledarima i kalendarima, misečnicima i mesecoslovima, kao i žanrovima u njima zastupljenim koji su prevashodno u funkciji prosvetiteljstva protestantske provenijencije: istoriografski tekstovi, priče iz klasične starine, putopisni žanrovi, basne, sentencije, pisma, retorski žanrouski oblici.
\end{abstract}

Ključne reči: Homo Europaeus, Habsburška monarhija, 18. vek, „prosvećena modernizacija“, Hrvati i Srbi, periodika, žanrovi

而 ko se ljudskoj istoriji priđe kao istoriji civilizacije, istoriji ideja, tj. ako se prepustimo evropeizaciji istorijske slike, Evropa jeste najznačajniji prostor na kojem dolazi u 18. veku do intenzivnog sažimanja i prožimanja uticaja Istoka i Zapada. Posebno značajno mesto zauzima Habsburška monarhija, ne toliko prostorno-geografski, već kao preoblikovani kulturni koncept prosvećenog apsolutizma, kao i centralno-istočni sa kulturnim tokovima u kojima protrajava vizantijska i pravoslavna tradicija. A kada je reč o interkulturalnim aspektima "prosvećene“ modernizacije, o rađanju evropejstva centralno-istočnog čoveka, svakako su važni hrvatsko-srpski odnosi i prožimanja, posebno kada je reč o stasavanju novog evropskog čoveka i ideje savremenog sveta kroz preispitivanje socijalnog, političkog i istorijskog konteksta diskusije o „evropskoj tradiciji“.

Osamnaesti vek kruna je ciklusa nastajanja Homo Europaeusa kao nosioca „modernosti“, krize svesti tokom tranzicije (između renesansnog humanizma i prosvetiteljstva) iz srednjovekovnog u savremno doba. Pitanje je koliko je u kulturološkom smislu Evropa tada bila moguća kao jedinstven duhovni organizam, kada se susreću balkanski pravoslavni svet sa katoličkim svetom, po mnogo čemu kao nastavci dve polovine Rimske imperije, uz dopri- 
nos Mediterana, njegovog sveta i kulture koja svetlošću ozaruje rađanje novog evropskog čoveka, te introvertnog Severa koji je postao prostor reformacije? Da li je i dokle oznaka granične linije Evrope sagledavane do Beča pretpostavljala da se preko te linije nalazi periferija, tranzicijski prostor između Zapada i velikog azijskog Istoka, onako kako je u naše vreme, književnik Boško Petrović na brdu kod Titela, kada se okrenuo na istok, osetio kako odatle na njega zija Azija? Nije li 18. vek vreme intenziviranja, koji vek ranije započetog, neprekidnog dijaloga Istoka i Zapada? Upravo su na tom planu bitni kulturološki odnosi Hrvata i Srba.

U kompleksu interkulturalnih aspekata „prosvećene“ modernizacije tičuće se Hrvata i Srba, osnova na kojima se projektuje nova slika evropske duhovnosti, svakako se moraju uzeti u obzir veze antičkog, srednjovekovnog i savremenog sveta. Prihvatanje antičkog sveta u zlatnoj harmoniji klasicizma, pri čemu se oslobađa fantazija i nastaje veliko buđenje, a antika svojim autoritetom daje novim idealima zeleno svetlo i istovremeno nudi model kulture koji se oslanja na racionalizam kao veliku ideju koja je iznad verovanja, tradicija, crkve, principa autoritarnosti, značilo je poricanje zastarele srednjovekovne misli, literature u znaku alegorija. Samo na primeru alegorije kao žanra možemo pratiti promene, počev od alegorije hrišćanske provenijencije do one baroknog tipa, te one sa novom ulogom u epohi prosvećenosti. I to na primeru jednoga pisca, Jovana Rajića na primer, ili na primeru pojedinačnog njegovog dela. Značajan udeo i uticaj na ovim prostorima imao je i protestantizam, kako onaj luteranski, čiji su centri u kulturološkom smislu gradovi (Getingen, Hale, Berlin, Vitenberg, Jena, Lajpcig, Amsterdam) tako, možda i u većoj meri, onaj koji je propovedao Kalvin, više prihvaćen u ruralnim sredinama. Živ je i dugotrajno delotvoran, takođe, tip civilizacije koju je osnovao vizantijski organizam, koji traje i posle pada Konstantinopolja u turske ruke, kao i grčko intelektualno nasleđe, pravoslavna vera, umetnost koja se razvijala u jugo-istočnom delu kontinenta. Potom, nezaobilazan je i uticaj Osmanlijskog carstva, islamske civilizacije Levanta, sve do post-vizantijskog helenstva, novog pravoslavlja i balkanskog romantizma. Sve je to kulturno obogaćivalo Evropu, upotpunjavalo njen kulturni mozaik.

Za pokušaj da se odgonetnu razvoj i suština dijaloga Istoka i Zapada, načini prožimanja tradicija kako velikih, tako u 18. veku državno još nepotvrđenih naroda, bitni su kulturni „koridori“, od Getingena na severu, do Transilvanije na istoku, od flamanskog sveta prema austrijskom, mađarskom, hrvatskom, srpskom, od univerzitetskih i književnih krugova Halea i Berlina prema onima u Budimu, Zagrebu, Sremskim Karlovcima, Sibiu, Jašiju, Bukureštu. Tu, najpre, treba istaći nezaobilazan udeo Grka i Jevreja. Grci veoma rano otvaraju protestantske škole (Dendrin i drugi) koje, neku deceniju kasnije, pohađaju Dositej Obradović i drugi „prosvetitelji“. Njihov je veliki uticaj u diplomatiji, na trgovinu i trgovačke puteve, snažno deluju u okviru pravoslavne crkve na jugo-istoku.

Judeizam je, pored helenizma i protestantizma, bio najprodornija civilizacijska sila naroda rasutog među drugim narodima. Izdeljeni po raznolikim, pa i jezički različitim dijasporama, upravo zahvaljujući načinu života u tim izolovanim sredinama, kako bi izišli iz geta oni se okreću stvaralačkoj snazi, individualnosti i praktičnoj realnosti, pre budućnosti nego prošlosti. U tome je suština nomadske strane jevrejskog mentaliteta. Tako su oni povezivali prostore, umne ljude, značajno delovali na kulturne tokove i uobličavanje modela evropskog čoveka centralno-istočnog evropskog prostora. Radovan Samardžić je u svojim istraživanjima valjano pokazao koliki je njihov udeo u jevrejsko-balkansko-italijanskom povezivanju. Da podsetim na trgovinske veze Jevreja iz Dubrovnika i onih u Carigradu, 
na njihov uticaj u kulturnim središtima Balkana, ali i Evrope, gde, u Lajpcigu, Haleu ..., postaju nosioci izdavačke delatnosti, osnivači knjižara, pokretači listova i magazina, osnivači najznačajnijih javnih, dvorskih i privatnih biblioteka tog vremena, inicijatori otvaranja škola, nosioci lekarstva, prenosioci informacija, ideja, naučnih eksperimenata. Svakako se mora uzeti u obzir i podrška masonskih organizacija, koje omogućuju predstavnicima „prosvetiteljstva“ malih naroda da putuju, borave u kulturnim središtima Evrope, Parizu, Londonu, da štampaju knjige, da budu predstavljeni svetu ostvarenim rezultatima na koje su planski bili usmeravani (na primer prvi rečnici narodnih jezika i prevodi Biblije na te jezike čime se dobijalo članstvo Biblijskog društva, koje je imalo značaj uključivanja u evropsku zajednicu). Tako će Dositej Obradović putovati u London, boraviće u Lajpcigu kod masona Brejtkopfta čitavu godinu da bi pripremio i uz njegovu podršku objavio žanrovski veoma razuđenu publikaciju Basne, načinjenu na magazinski način, na način cvetnika, sa namerom da se nastavi kao periodik. Reč je, naime, o buđenju umova, otkrivanju i promovisanju određenih ličnosti koje će koordinirati dijalog sa svetom. To su ljudi koji sa sobom nose knjige i ideje, iz toga proizilazi ona Dositejeva poruka: „Knjige, knjige, a ne zvona i praporci!“”

U tom kontekstu važne su biblioteke preko kojih prodire i otelotvoruje se slika savremenog čoveka. Osniva se biblioteka u Sremskim Karlovcima, osniva je episkop Baćanji Ignjac (Batthyani Ignac) u Alba Juliji, osnivanjem plemićke biblioteke u Tirgu Murešu Teleki Samuel otvara put evropejstvu čitavoj oblasti, biblioteke osnivaju franjevački monasi u Aradu, Klužu, Temišvaru. Sečenjijeva (Szechenyi Ferenc) biblioteka učinila je neizmerno mnogo za stasavanje plejade pripadnika epohe „prosvećenosti“ malih naroda koji su živeli u Austrijskom carstvu. Univerzitetska štamparija u Budimu, značajna za univerzitetsko okruženje, u kojoj najznačajnija dela štampaju autori koji pripadaju malim narodima od 1777-1849, na desetine jezika, odigrala je ulogu od prvorazrednog značaja za povezivanje i prožimanje mnogih kultura koje je politički povezivalo Austrijsko carstvo. Ona odražava na najbolji način ideologiju prosvetiteljstva kada je reč o sakupljnju i širenju saznanja. U Beč, Budim i manje centre stižu knjige Erazma Roterdamskog, Lutera, Rusoa, Voltera.

Rumunski istoričar Viktor Nojman (Viktor Neumann) u knjizi Iskušenja Homo Europaeusa (Tentatia lui Homo Europaeus, 2006), 2011. godine prevedene na srpski jezik, prevashodno iz ugla srednjo-jugo-istočne Evrope, uspešnost procesa nastajanja evropskog čoveka kao nosioca univerzalnih ideja nove civilizacije objašnjava čarobnim trouglom koji, kao pokretačku silu bez koje se ta veličanstvena tranzicija ne bi ni odigrala, određuju: zbližavanje - upoznavanje - dijalog. U 18. veku, ističe, postoji velika glad za zbližavanjem, upoznavanjem i dijalogom. Po Nojmanu mnogo elemenata čini jedinstvenim prostor koji pokriva Hrvatska, Srbija i Banat, dakako podrazumevajući i rumunski deo, kao oblast kulturnih preplitanja Rumuna, Nemaca, Srba, Mađara, Jevreja, Slovaka, Turaka, Bugara, Roma. Po njemu to su tri glavne tačke konvergencije centralno-istočnog mentaliteta, ali i jugo-istočno evropskog. Ovi prostori uključuju „kako elemente Mitteleuropa-e, tako i elemente koji dolaze sa Balkana, Islama, hebrejskog istoka te jugo-istočne sentimentalnosti, tako i južnjački temperament mediteranskog porekla i kulturu i tradiciju nemačkog severa“. Po njemu je tu bilo manje rigorozno i tolerantnije pravoslavlje a isto tako i katolicizam i reformacija koji su u svojim raznim oblicima omogućili širenje zapadnih ideja na ovom delu kontinenta. Posebno značajnim smatra činjenicu da je preko slovenskog jezika kojim su govorili i sporazumevali se narodi na južnoslovenskom prostoru uspostavljen kontakst sa grčkim i vizantijskim stvaraocima kasnog antičkog doba. 
Ovakav Nojmanov pristup može biti znatno upotpunjen ako se Dunav, iako geografski pojam, sagleda kao kulturni koridor. Uz tu veliku reku nižu se varadi, utvrde, gradovi koji se šire i izvan zidina, u kojima stasava građanski stalež koji donosi nove civilizacijske vrednosi: Beč, Bratislava, Sent Andreja, Budim, Novi Sad, Petrovaradin, Sremski Karlovci, Beograd ... Nije reč samo o reci i priobalju, već o slivu naroda, o protoku ideja, o prožimanju zahvaljujući pre svega rečnom saobraćaju i trgovini. Reč je o reci koja nikada nije mogla biti i ostati limes koji deli narode, sa mostovima koji su ne samo simbolično ugrađeni u kulturu tog prostora kao arhitektonski sloj, reč je o Homo Danubiusu. To je tek jedan od vidova umnožavanja evropskog novog čoveka, a mogućnost tog umnožavanja već predstavlja snagu prostora o kojem govorimo i njegovog kulturnog ozračenja. Reč je o slivu koji podrazumeva sve reke koje se u Dunav ulivaju, i one manje reke koje se ulivaju u te reke. Reč je o Podunavlju, Slavoniji, Sremu, Bačkoj, Banatu, rumunskoj i bugarskoj strani Dunava, ali i o Moravi sa svojim pritokama, Resavskoj dolini sa prepisivačkim školama, o Savi, Tisi, Tamišu, Timoku. Sever „prosvetiteljstva“ stiže Dunavom do Crnog mora. Niz Dunav se išlo u Rusiju, lađama se spuštalo do Stambola. To je bio koridor povezivanja srednjo-istočnog dela Evrope sa Levantom. Tim lađama, na kojima se, za razliku od Vavilonske kule, govorilo saglasnim jezicima, ploviće i Dositej, zajedno sa predstavnicima mnogih vera i naroda.

Nojmanov pristup može biti upotpunjen i ako se krene iz ugla književnog stvaralaštva. Kada je reč o 18. veku svakako je od značaja pitanje početaka periodike kod Hrvata i Srba u evropskom kontekstu, mislim pre svega na nemačke, mađarske i ruske uzore. U žiži mog pristupa jesu praperiodični oblici: cvetnici, magazini, zabavnici, koledari i kalendari, misečnici i mesecoslovi, kao i žanrovi u njima zastupljeni, koji su prevashodno u funkciji prosvetiteljstva. U ovim godišnjacima periodičnog karaktera objavljuju se prevodi pesama i poučnih pripovedaka, prepuni su poslovica, izreka, iskrica, poučnih pisama u kojima se na „književan“ način savetuju čitaoci o poslovima zemljedelstva, spravljanja vina, o zdravlju, o ponašanju i vaspitanju, o odnosu prema veri. Upravo ove forme periodika magazinskog tipa, „od svega po malo“, rezultat su ideja prosvećenosti protestantske provenijencije, želje da se nauka i opšte znanje približi narodu, da ne budu privilegija samo odabranih, bilo da je reč o kleru ili dvorskim krugovima, već da se na zanimljiv način približe širem čitalačkom krugu i tako doprinesu demokratizaciji nauke i kulture, „prosvećenoj“ modernizaciji ukupnog društva. Ovde svakako treba podrazumevati i druge publikacije tipa „knjiga za narod", jer u pitanju je čitav sistem prosvetiteljskog delovanja sa ciljem da se vaspostave uzori, čak i kanoni epohe prosvećenosti. Dakako da akcent treba staviti na male narode u velikom carstvu koji su krenuli putem sustizanja velikih kultura. Okrenuti jedan drugom oni su lako prihvatali i preuzimali priloge iz ovakvih publikacija, međusobno sarađivali u istim publikacijama. U tom kontekstu treba sagledavati i rukopisne almanaške forme, lire i pesenike, rukopisne pesmarice, koje se prepisuju i idu iz ruke u ruku. I ova rukopisna dela odigrala su značajnu ulogu u povezivanju i suživotu mnogih naroda. Tako u velikoj pesmarici iz tridesetih godina 18. veka nastaloj u Sakolči, pored pesama na nemačkom i mađarskom, slovačkom, nalazimo i srpske pesme o slavi, hrvatske vinske, pa i jednu sa naslovom „bošnjačka“.

Književni žanrovi kao nosioci novih ideja mogu biti posredan ugao sagledavanja suštine epohe „prosvećenosti“. Žanrovski potencijal 18. veka čini svojevrsnu silu uobličavanja $H o$ mo Europaeusa i, s razlogom, promeće se kroz čitav 19. vek.

Istoriografski tekstovi donose novi pristup istoriji. Istorije i hronike imaju višestruki cilj. Koristeći se manje istorijskim činjenicama, a više predanjem i usmenim stvaralaštvom, pa i 
mistifikacijama kako bi se rekonstruisali kontinuiteti koji mogu da doprinesu nacionalnim interesima (Hronike Đorđa Brankovića), ovakvi spisi prenose se i u rukopisnom obliku, a u njima se teži celovitijem pristupu istorijskim zbivanjima na nekom prostoru i propagira ideja ujedinjenja porobljenih naroda, Slovena, Ilirika (Jovan Rajić, Istorija raznih slovenskih narodov, najpače Bolgar, Horvatov i Serbov).

Priče iz klasične starine poslužile su piscima epohe „prosvećenosti“ da direktno uvedu starogrčku i rimsku tradiciju, ali reč je o preradama, sa posve novim funkcijama klasičnog štiva. Kada je reč o ovom žanru u literaturama malih naroda, osnovni cilj jeste da se čitaoci upoznaju sa tradicijom vrednom pamćenja kako bi se u novom dobu mladi, vaspitavani stereotipima, pripremili da se bore za zajednicu - nacionalistička struja prosvetiteljstva - da se kod njih podstakne jačanje nacionalne svesti i opredeljenost za nacionalne težnje malih naroda da obnove ili stvore svoju državu.

Putopisni žanr takođe doživljava transformaciju. Potukanje, odisejade iz klasične literature, kada su cilj i način lutanja određeni mitološkim nasleđem (traženje zlatnog runa, borba sa mitskim bićima), te hrišćanska hodočašća (u prvom planu su mošti, komad časnog krsta; crkva i religija određuju ponašanje, šta je bitno gledati i činiti tokom putovanja), zamenjuju otkrivalački putopisi sa alegorijskom konotacijom (prevedeno alegorijsko putovanje u Dositejevoj knjizi Basne tiče se izbora pravoga puta u životu). Dok Aleksandar Makedonski osvajački stiže do Kine, Marko Polo Kinu otkriva, sve je u simbolici Mobi Dika, hitnutog koplja u kita, u nepoznat predeo, ili je reč o modelu nauke koja pobeđuje (u 18. veku na južnoslovenskom prostoru učestalo se prevodi roman Danijela Defoa Robinson Kruso). Putopisna autobiografska Dositejeva proza ima, pre svega, svrhu da se upozna novo, ljudi pre svega, drugi narodi, ali i predeli, pri čemu preteže ono urbano, delo čoveka. Krajnji cilj jeste da se u cenru putopisnog teksta nađe novi evropski čovek univerzalnog tipa, otvoren, bez straha da se povede za svojim umom, oslobođen vekovne navike da dogmom bude vođen kako da misli i dela.

Basne, svima podobne kao iskustvo, u 18. veku su jedan od načina povezivanja književnika sa helenskim svetom, ali su, istovremeno, oplemenjene ogledima o novim idejama, o veri, dobrodjetelji (Dositejev credo „dela su večita tek" preneće u 19. vek Jovan Popović Sterija), o ličnosti koja mora sebe da nađe i slobodno se ispolji, o nauci i moći znanja, protiv dogmi i sujeverja. Basne su pune programskih sentencija, parafraza usmenih poslovica $i$ izreka, biblijskih poslovica i onih preuzetih iz literature i govorne prakse susednih naroda. Da je u pitanju deo programa epohe „prosvećenosti“ najbolje govori što je Jovan Muškatirović, u predgovoru drugom izdanju svoje knjige Pričte iliti poslovice tjemže sentencije iliti rječenija (1787; 1807) istakao da su mu oko ove knjige pomogli Dositej Obradović i Atanasije Sekereš.

Sentencije kao žanr, beležene i štampane uazbučene poput rečnika mudrosti, postaju zaključni deo žanrovski veoma složene Dositejeve knjige Basne. Dositej objavljuje prevod sentencija sa engleskog („sad iz ingleskog vrta sadovi“), na koje je bio upućen. Čak i kada preuzimaju lascivne poslovice, izreke ili sentencije, pisci 18. veka biraju one koje oslobađaju čoveka, kao i one koje su indirektna kritika oblapornosti, predavanja strastima umesto zaokupljenosti s dobrodjetelji. Najzad, prevedene, tako kako se preuzimaju i nude čitaocima, one, potom, ulaze u narod i doživljavaju usmenu redakciju da bi, kasnije, bivale zabeležene kao narodne. Ima tu i latinskih, okrenutih sigurnim izvorima klasike, ali i mađarskih, nemačkih. Ovaj žanr u 18. veku funkcioniše kao svojevrstan način kulturološkog prožimanja. 
Pisma su u epohi „prosvećenosti“ korišćena kao žanr pogodan za protok ideja novog Evropejca, čak i kada je reč o putopisnim pismima. Epistolarnost kao način formulisanja ideja, iskazivanja spremnosti za prožimanje, dijalog, prihvatanje novoga, širokog prihvatanja konvergencije posebnih oblasti kultura koje imaju svoje posebnosti sa ciljem da se utvrdi zajednički imenitelj, moćno su sredstvo epohe „prosvećenosti“. Tako Dositejevo pismo Haralampiju, u kojem dosta rano iznosi osnove programa kojeg se, potom, decenijama dosledno pridržavao i ostvarivao ga, nije posve originalno delo kako mnogi ističu. Takvih pisama bilo je puno u to vreme, imala su funkciju cirkulara kojima su prenošene gotove programske poruke, tokom prenošenja prilagođene čitaocima određene regije. Dositejevo pismo valja čitati, pre svega, u kontekstu univerzalnosti kao odlike Homo Europaeusa.

Retorski žanrovski oblici pokazuju da je, po ugledu na klasičnu retoriku, u 18. veku stupio na scenu novi vid retorike. To su tekstovi kojima se retor obraća u pisanom obliku podrazumevajući čitaoce kao slušaoce. Odlikuje ih ton usmenog obraćanja. U tom ključu bi i čitatelj Dositejeve prepiske mogao da njegovim pismima pristupi iz sasvim novog ugla. Poređenje sa, takođe bogatom, prepiskom Vuka Karadžića, pokazalo bi da je reč o dva tipa prepiske - prosvetiteljske i nacionalističkog tipa. Kod Vuka je naglašena ideja nacionalnog programa. Nije reč samo o folkloru, opisu narodnog života, usmenom stvaralaštvu, već o povećanom interesovanju za noviju istoriju započetu Prvim srpskim ustankom, koja se uzima kao temelj obnove nacionalne države.

Žanrovski potencijal 18. veka obeležava osobita hibridnost žanrova, njihovo prožimanje. $\mathrm{U}$ basnama nalazimo preoblikovane u basne priče iz klasične starine, basne o bogovima, filozofima itd. Hibridnost čini žanrove žilavim i omogućuje im da traju kroz vreme, da se promeću kroz periodiku i kalendare duboko u 19. veku. To je matrica pisane škole epohe prosvećenosti (knjiga u prvom planu, ono što je štampano jeste gotovo sveto). Homo Europaeus je kroz takve žanrove stekao moć izražajnosti veoma blizak idealu idejne iniverzalnosti, u kojoj je u prvom planu $j a$. To $j a$ i pripoveda i prima, i učestvuje u basni, prima sentenciju da bi je preneo drugom (brojni prepisi ižica, alfabeta), da bi stvorio univerzalni sistem promišljanja pojava, istorije, nauke, života, vere, umetnosti, svekolikog stvaranja. Sva ta dela jesu i ogled i naravoučenije, pokušaj da se ne petrificira zaključeno, da se ne dogmatizuje jednom za navek, već da se veruje da je sve podložno preispitivanju, traženju novoga, kretanju unapred, pri čemu se umni ljudi, polemikom, razmenom ideja, ispomažu. U osnovi je reč o principu prave nauke, naučnog promišljanja prvog reda. Samo tako se može, pretpostavkom, iskušavanjem, u nauci nešto otkriti. Ogled je kruna žanrovskog umrežavanja epohe „prosvećenosti“, nešto najvrednije što nam je ova epoha poklonila. Nisu to više klasična sofistička filozofska vežbanja logike, promišljanja - ovo je filozofija na delu.

\section{$\cos$}

\section{Potential of THE I $8^{\text {TH }}$ CENTURY'S LITERARY STYLES AND HOMO EUROPAEUS}

If one approaches history of mankind as a history of civilization, a history of ideas, Europe in the $18^{\text {th }}$ centrury is the most relevant frame of intensive encounters and condensations of Western and Eastern cultures. The Habsburg Monarchy plays a particularly important role in cross-cultural exchanges. This is not that much due to its geocultural position, as it is up to its reformulated cul- 
tural concept of an enlightened apsolutism based on dynamic encounters of Western European and Eastern, primarily Byzantine traditions. Focusing on intercultural aspects of the Habsburg enlightened apsolutism, on the emergence of modern European humanism in Central-Eastern Europe, Croato-Serbian relations and encounters are particularly important. This article focuses on the emergence of modern South Slav journals, in particular among Croats and Serbs, in their European contexts. German, Hungarian and Russian models and experiences used to be the most relevant. Those used to be originally in function of the enligthenment of Protestant origine.

Keywords: Homo Europaeus, Habsburg Monarchy, the $18^{\text {th }}$ century, 'enligthened modernization', Croats and Serbs, periodicals and journals, literary styles

\section{$\cos$}

\section{Literatura}

GRBIĆ, Dragana. „Žanrovi u prvim srpskim novinama Serbskija povsednevnija novini“, Žanrovi u srpskoj periodici, zbornik radova, uredila Vesna Matović. Beograd - Novi Sad: Institut za književnost i umetnost - Matica srpska, 2010, 105-127.

MATICKI, Miodrag, Bibliografija srpskih almanaha i kalendara, knj. I. Beograd: SANU, 1986.

MATICKI, Miodrag. Letopis srpskog naroda. Tri veka almanaha i kalendara. Beograd: Institut za književnost i umetnost - Biblioteka Matice srpske, 1997.

MATICKI, Miodrag. „Susreti kultura u delu Dositeja Obradovića“, Susreti kultura, zbornik radova. Novi Sad: Filozofski fakultet, 2006, 501-504.

MATICKI, Miodrag. „Počeci srpske književne periodike. Dositejev cvetnik Basne (Lajpcig, 1788) u časopisnom i žanrovskom kontekstu“, Naučni sastanak slavista u Vukove dane, 39/2. Beograd: 2010, 387-394.

MATICKI, Miodrag. „Počeci nove srpske književnosti u prvim periodičnim publikcijama namenjenim mladima“. U čast Pera Jakobsena, zbornik radova, priredili Dejan Ajdačić i Persida Lazarević Di-Đakomo. Beograd: SlovoSlavia, 2010, 325-330.

MATICKI, Miodrag. „Žanrovski potencijal srpske književne periodike osamnaestog veka“, Žanrovi u srpskoj periodici, zbornik radova, uredila Vesna Matović. Beograd - Novi Sad: Institut za književnost i umetnost - Matica srpska, 2010, 75-102.

NEUMANN, Viktor. Tentatia lui Homo Europaeus. Bucharest: Editura Eminescu, 1006.

NOJMAN, Viktor. Iskušenja Homo Europaeusa. Radanje savremenih ideja u centralnoj i jugo-istočnoj Evropi. Prevod s rumunskog Milisav Firulović. Beograd: Pešić i sinovi, 2011.

STEFANOVIĆ, Mirjana D. Biblioteka srpske književnosti. Beograd: Čigoja, 2007.

ŠAFARIK, Pavel Josif. Istorija srpske književnosti. Za štampu, prema rukopisu iz 1834. godine, priredila Mirjana D. Stefanović. Novi Sad: 2004. 